\title{
Uso de agregado miúdo reciclado em matrizes cimentícias para compósitos reforçados com fibras de sisal
}

\author{
Daniele Oliveira Justo dos Santos ${ }^{1}$, Cintia Maria Ariani Fontes ${ }^{2}$ \\ Paulo Roberto Lopes Lima ${ }^{2}$
}

\author{
${ }^{1}$ PPGECEA/UEFS Av. Transnordestina, s/n, Novo Horizonte, CEP: 44036-900, Feira de Santana, BA \\ e-mail: danielejusto@gmail.com \\ ${ }^{2}$ PPGECEA/UEFS, Departamento de Tecnologia, Av. Transnordestina, s/n, Novo Horizonte, CEP: 44036-900, Feira de \\ Santana, BA \\ e-mail: cintiafontes@gmail.com; lima.prl.uefs@gmail.com
}

\section{RESUMO}

O elevado consumo de recursos não renováveis associado à geração de resíduos sólidos e gasto energético vem incentivando a busca por materiais sustentáveis que possam ser utilizados na construção civil. Os materiais compósitos com fibras vegetais, renováveis e biodegradáveis, surgem como uma alternativa para minimizar o impacto ambiental e tem potencial para a aplicação em elementos construtivos. Para isso, no entanto, é importante a utilização de uma matriz adequada que permita uma distribuição adequada das fibras, evitando o enrolamento das fibras e a incorporação de vazios durante o processo de mistura e lançamento do material em estado fresco. O presente estudo propõe o desenvolvimento de matrizes cimentícias autoadensáveis adequadas para uso em compósitos com alto teor de fibras. Foi utilizado o agregado miúdo reciclado com alto teor de finos, proveniente do beneficiamento de resíduos de concreto, em substituição a $10 \%$ e $20 \%$ do agregado miúdo natural. Ensaios de mini slump, absorção de água por imersão e capilaridade, retração por secagem e resistência mecânica foram realizados nas matrizes. Compósitos com 4\% e 6\% de fibras de sisal de 40 $\mathrm{mm}$ foram produzidos e avaliados quanto a resistência mecânica. $\mathrm{O}$ efeito do agregado reciclado sobre a matriz demonstra um aumento da resistência à compressão, manutenção da absortividade e incremento na porosidade e retração. Com o uso de matrizes autoadensáveis foi possível produzir compósitos homogêneos com até $6 \%$ de fibra curta de sisal, minimizando a redução de resistência mecânica pela adição das fibras e, dessa forma, aumento a potencialidade do material para uso estrutural ou não estrutural.

Palavras-chave: Resíduo de concreto, agregado miúdo reciclado, fibras de sisal, argamassa autoadensável.

\begin{abstract}
The high consumption of non-renewable resources and energy associated with the generation of solid waste has encouraged the search for sustainable materials for civil construction. The composite materials with vegetables fibers, renewable and biodegradable, arise as an alternative to minimize environmental impact and to produce constructive elements. For this, however, it is important to use an appropriate matrix to allow adequate distribution of fibers, avoiding the winding of the fibers and the incorporation of voids during the mixing and casting processes. This study proposes the development of appropriate matrices to development of composites with high content of sisal fibers. Concrete recycled aggregate with high content of fines was used to replace $10 \%$ and $20 \%$ of the aggregate natural. Water absorption tests, by immersion and capillary, shrinkage test and mechanical strength tests were carried out in matrices. Composites with $4 \%$ and $6 \%$ sisal fibers (length of $40 \mathrm{~mm}$ ) were produced and evaluated for mechanical strength. The effect of recycled aggregate on the matrix demonstrates an increase in compressive strength, maintenance of absorptivity and increase of porosity and shrinkage. Using selfcompacting matrices was possible to produce homogeneous composites containing up to $6 \%$ short sisal fiber, minimizing the reduction in mechanical strength by the addition of the fibers and thus increasing the capability of the material for structural or non-structural use.
\end{abstract}

Keywords: Waste concrete, fine recycled aggregate, sisal fibers, self-compacting mortar.

\section{INTRODUÇÃO}


A utilização de materiais sustentáveis na produção de elementos construtivos é uma alternativa para redução do impacto ambiental do setor da construção civil, que apresenta alguns indicadores preocupantes quanto ao consumo de recursos não renováveis, gasto energético e geração de resíduos sólidos. De acordo com o Departamento Nacional de Produção Mineral (DNPM) o consumo de areia para a construção no ano de 2013 foi de 377.247.785 toneladas [1], apesar de ser um recurso natural abundante, se não forem protegidos serão esterilizados pela urbanização. Outro indicador importante e que exige atenção especial é a destinação final dada aos resíduos de construção e demolição (RCD); de acordo com a Abrelpe [2], os municípios brasileiros coletaram mais de 35 milhões de toneladas de RCD somente em 2012 e é um valor tende a aumentar com a crescente urbanização e envelhecimento das construções existentes.

Os compósitos reforçados com fibras vegetais apresentam-se neste contexto como um material promissor, visto que, em comparação com fibras manufaturadas (poliméricas, asbesto, aço ou vidro), as fibras de sisal, coco, juta ou curauá provenientes de fontes renováveis, apresentam baixo custo de produção e são abundantes nos países tropicais [3]. Esse fato tem incentivado o desenvolvimento de vários produtos com essas fibras, em matrizes poliméricas ou cimentícias, que apresentam aumento da resistência mecânica, conforto térmico e tenacidade $[4,5,6]$.

Porém, a utilização de fibras curtas, dispersas em matrizes cimentícias convencionais tende a reduzir a trabalhabilidade da mistura, o que dificulta a homogeneização das fibras e aumenta a porosidade do compósito endurecido. Como resultado, há uma redução importante de resistência mecânica [4], mesmo com a introdução de baixos teores de fibra. O desenvolvimento de materiais compósitos de alto desempenho só é possível, então, através da modificação da matriz com a utilização de aditivos químicos, adições minerais e pela utilização de agregados finos adequados, para garantir a homogeneização das fibras na matriz e a fluidez da mistura $[7,8,9]$.

Com a crescente redução das jazidas de agregados para concretos e argamassas, a utilização de agregados reciclados tem sido cada vez mais comum, sendo que a utilização do agregado oriundo de resíduos de concreto é atualmente recomendada para concretos com fins não estruturais [10] ou estruturais [11]. Diversos estudos sobre a utilização desse agregado em argamassas $[12,13]$ têm demonstrado que ele representa uma boa alternativa ao agregado natural, sendo seu uso inclusive já testado como filer em matrizes de materiais compósitos [14]. Em contrapartida, algumas características do agregado reciclado, como alta absorção, porosidade e alto teor de finos pode dificultar a utilização do resíduo de concreto como inerte, por afetar diretamente as propriedades da argamassa no estado fresco e no estado endurecido. A alta absorção de água do agregado afeta diretamente a trabalhabilidade da mistura [14] e, para minimizar esse problema tem sido utilizada taxas de compensação de água durante a dosagem da mistura [15] ou adição de superplastificante [16]. No estado endurecido, uma das principais preocupações sobre o uso de agregado fino tem sido a possibilidade de aumento da deformação diferida, com implicações na retração por secagem [17] e na fluência do concreto [18]. Para evitar problemas de longo prazo, o uso de agregado finos em aplicações estruturais tem sido limitado a teores de até $20 \%$, em substituição ao agregado fino natural [11].

Acredita-se que o uso do agregado reciclado de concreto para produção de matrizes de materiais compósitos, que necessitam de materiais com granulometria adequada, possa contribuir para melhoria do desempenho sem aumento do custo, visto que trata-se de um agregado que já irá sofrer beneficiamento (moagem e peneiramento) para uso na construção civil.

No caso das fibras de sisal, para que não ocorra enrolamento das mesmas e formação de novelos durante a mistura Gram et al. [19] recomendam um volume máximo de fibras de 1,5\% (para fibras com $60 \mathrm{~mm}$ ) ou de 3\% (para fibras com $15 \mathrm{~mm}$ ) quando se utiliza matrizes de argamassas convencionais, sem aditivos ou adições. Por outro lado, com a utilização de uma matriz mais apropriada, utilizando superplastificante e agregado de dimensão reduzida, Lima et al [9] obtiveram uma matriz com consistência adequada para que o reforço com até $6 \%$ de fibras (de até $50 \mathrm{~mm}$ ) pudesse ser incorporado, o que demonstra que a modificação da matriz pode permitir compósitos mais adequado.

O objetivo deste trabalho é avaliar o efeito da adição agregado reciclado sobre as propriedades físicas e mecânicas de matrizes cimentícias autoadensáveis e sobre as propriedades mecânicas dos compósitos com elas produzidos. O agregado reciclado, proveniente do beneficiamento de resíduos de concreto, foi utilizado como substituição de parte do agregado miúdo natural em teores, em massa, de $10 \%$ e 20\%. Ensaios de absorção por imersão, absorção capilar, retração por secagem e resistência mecânica foram realizados na matriz. Para avaliação do potencial de utilização da matriz reciclada, compósitos reforçados com teor de fibra, em volume, de $4 \%$ e $6 \%$ de fibras de sisal foram produzidos e avaliados quanto a resistência à compressão e resistência à tração por compressão diametral. 


\section{MATERIAIS E MÉTODOS}

Foram utilizadas fibras de sisal provenientes do município de Conceição do Coité, Bahia. Inicialmente as fibras foram lavadas em água quente, para retirada de resíduos superficiais, oriundos do processo de extração. Posteriormente passaram por um tratamento em ciclos molhagem-secagem, de acordo com Ferreira et al [15] para reduzir sua capacidade de absorção de água e melhorar sua aderência. As fibras foram cortadas em tamanho de $40 \mathrm{~mm}$ e adicionadas em volume de $4 \%$ e $6 \%$.

Foram utilizados como aglomerante uma blenda composta de 33\% de cimento Portland CP II F-32, $27 \%$ de metacaulinita e $40 \%$ de cinza volante, com o objetivo de produzir uma matriz livre de hidróxido de cálcio e quimicamente compatível com a fibra de sisal. A quantidade de adições minerais foi definida em estudo anterior [20], utilizando os mesmos materiais, em que se comprovou, através de análise termogravimétrica, o total consumo do hidróxido de cálcio formado pelo processo de hidratação do cimento. A presença da cinza volante visa garantir uma maior trabalhabilidade nos compósitos e melhor homogeneização das fibras.

Para desenvolvimento da matriz autoadensável foi utilizado um aditivo superplastificante de terceira geração a base de éter policarboxílico que atua como dispersante do material cimentício. Tal aditivo possui $30,86 \%$ de sólidos e massa especifica variando entre 1,076-1,107 g/cm3. Para evitar a exsudação e a segregação e manter a coesividade das argamassas foi utilizado um agente modificador de viscosidade a base de polímeros de celulose de alto peso molecular, massa específica real variando entre $0,68-0,72 \mathrm{~g} / \mathrm{cm}^{3}$. A dosagem do agente modificador de viscosidade foi de $0,05 \%$ sobre a massa dos aglomerantes.

Foram usados dois tipos de agregados: o agregado natural, de origem fluvial e composto de quartzo; e o agregado reciclado, proveniente da fase concreto de um resíduo de demolição de uma edificação, composto originalmente por argamassa (56\%), cerâmica $(27 \%)$ e concreto $(17 \%)$, separados manualmente por inspeção visual. $\mathrm{O}$ agregado reciclado foi produzido pela britagem da fase concreto em britador de mandíbula e posterior peneiramento. Os resultados da caracterização dos agregados constam na Tabela 1. A Figura 1 mostra a curva granulométrica dos agregados.

Tabela 1: Caracterização dos agregados

\begin{tabular}{c|c|c}
\hline CARACTERÍSTICAS & AGREGADO NATURAL & AGREGADO RECICLADO \\
\hline Diâmetro máximo $(\mathrm{mm})$ & 1,18 & 2,36 \\
\hline Módulo de finura & 1,73 & 2,11 \\
\hline Material pulverulento $(\%)$ & 0,95 & 14,36 \\
\hline Absorção de água $(\%)$ & 0,03 & 6,11 \\
\hline Massa específica $\left(\mathrm{g} / \mathrm{cm}^{3}\right)$ & 2,65 & 2,60 \\
\hline
\end{tabular}

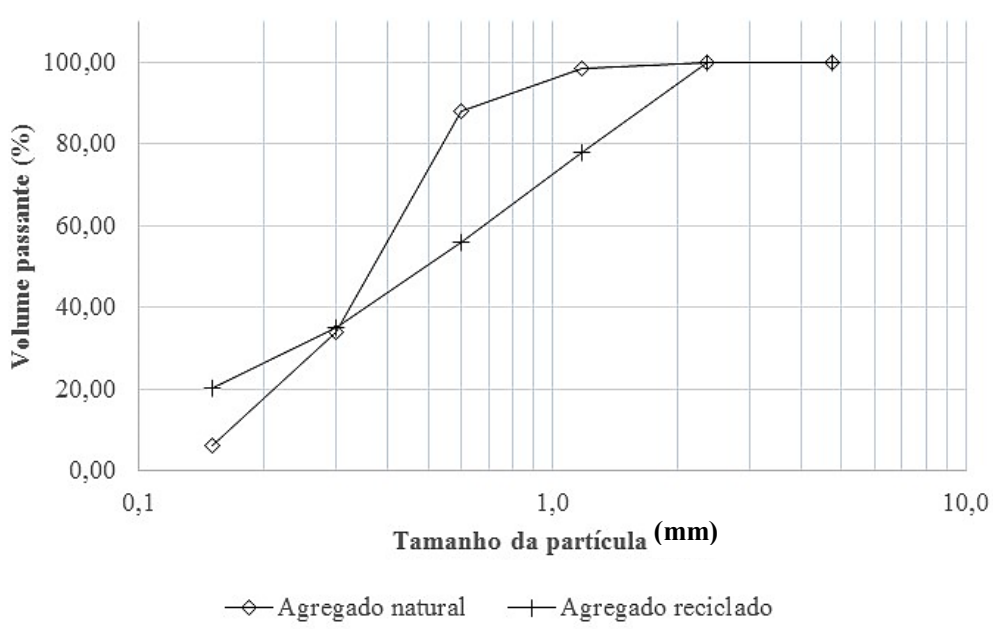

Figura 1: Granulometria dos agregados.

As matrizes foram moldadas no traço, em massa, de 1:0,5:0,45 (aglomerante:agregado:relação água/aglomerante), com base em estudos anteriores [4]. Foram produzidas misturas com agregado natural e com substituição de $10 \%$ e $20 \%$, em massa, por agregado reciclado. Os compósitos foram produzidos com adição de fibra de sisal de $4 \%$ e $6 \%$, em volume. Na Tabela 2 estão apresentadas as composições das mistu- 
ras estudadas.

Tabela 2: Traço das misturas $\left(\mathrm{kg} / \mathrm{m}^{3}\right)$.

\begin{tabular}{c|c|c|c|c|c|c|c|c|c}
\hline \multirow{2}{*}{ MATERIAIS } & \multicolumn{3}{|c|}{ MATRIZES } & \multicolumn{3}{c|}{ COMPÓSITOS COM 4\% DE } & \multicolumn{3}{c}{ COMPÓSITOS COM 6\% DE } \\
\cline { 2 - 10 } & REF & $\mathbf{1 0 R C}$ & $\mathbf{2 0 R C}$ & REF4F & 10RC4F & 20RC4F & REF6F & 10RC6F & 20RC6F \\
\hline Cimento & 314,52 & 314,41 & 314,31 & 301,74 & 301,64 & 301,54 & 295,73 & 295,64 & 295,54 \\
Cinza Volante & 381,24 & 381,11 & 380,98 & 365,75 & 365,63 & 365,51 & 358,46 & 358,35 & 358,23 \\
Metacaulinita & 257,34 & 257,25 & 257,16 & 246,88 & 246,8 & 246,72 & 241,96 & 241,88 & 241,81 \\
Areia Natural & 476,55 & 428,75 & 380,98 & 475,18 & 411,33 & 365,51 & 448,08 & 403,14 & 358,23 \\
Areia Reciclada & - & 47,64 & 85,24 & - & 45,7 & 91,38 & - & 44,79 & 89,56 \\
Água & 428,9 & 428,75 & 428,6 & 411,47 & 411,33 & 411,19 & 403,27 & 403,14 & 403,01 \\
SP & 24,71 & 24,71 & 30,86 & 59,26 & 68,13 & 74,02 & 58,08 & 66,77 & 72,55 \\
Fibra & - & - & - & 36,57 & 36,56 & 36,55 & 53,77 & 53,75 & 53,73 \\
\hline
\end{tabular}

Para a produção das matrizes e dos compósitos foi utilizado um misturador com capacidade de 20 dm3. Inicialmente os materiais secos foram pesados e ensacados até a hora da moldagem. As etapas do processo de produção estão descritas a seguir: com o cimento e a cinza volante previamente homogeneizados dentro da cuba, a água foi sendo adicionada continuamente. Ao mesmo tempo foi colocada a areia com metacaulinita, (por 4 minutos). Para as matrizes recicladas, o agregado reciclado foi homogeneizado nessa etapa do processo. Essas etapas foram realizadas com a argamassadeira na velocidade baixa. Após esse tempo, a argamassadeira foi desligada por 30 segundos para a retirada do material aderido a cuba. Em seguida, misturou-se por mais 2 minutos na velocidade alta, antes do lançamento do reforço fibroso. Este foi realizado por cerca de 6-9 minutos em velocidade baixa, de modo a facilitar a dispersão das fibras dentro da mistura e evitar o enovelamento. Por último, foi adicionado o agente modificador de viscosidade.

Cabe ressaltar que o agregado reciclado foi utilizado na condição seca e a compensação do efeito da absorção de água pelo agregado reciclado foi feita através da utilização do superplastificante. De modo a verificar a autoadensibilidade das matrizes foi realizado o ensaio de mini slump.

$\mathrm{O}$ efeito do teor de agregado reciclado sobre o comportamento da matriz foi avaliado através do ensaio de absorção de água por imersão, conforme NBR 9778/09 [21], do ensaio de absorção de água por capilaridade, conforme NBR 9779/95 [22], Figura 2-a, e do ensaio de retração por secagem, de acordo com a ASTM C 157/03 [23], Figura 2-b. No ensaio de retração, foi utilizado um corpo de prova de maior dimensão (100 mm x $100 \mathrm{~mm}$ x $285 \mathrm{~mm}$ ) para que, futuramente, possa ser comparado com estudos sobre a retração de compósitos, que não devem utilizar corpos de prova de argamassa devido ao tamanho das fibras. O efeito da adição do agregado reciclado sobre o comportamento dos compósitos foi avaliado pela medida da resistência à compressão axial, conforme NBR 5739/07 [24], Figura 2-c, e resistência à tração por compressão diametral, conforme NBR 7222/94 [25], Figura 2-d. Foram moldados 3 corpos de prova para cada mistura e para cada ensaio, os quais foram mantidos imersos em água por 28 dias antes dos ensaios.

Para os ensaios de absorção de água por imersão e por capilaridade foram moldados corpos de prova cilíndricos de dimensões $50 \mathrm{~mm}$ de diâmetro e $100 \mathrm{~mm}$ de altura. No ensaio de absorção por capilaridade, as amostras foram seladas em sua lateral para garantir o fluxo unidirecional e evitar perda de umidade.

A absorção de água por capilaridade por unidade de área, i, em materiais de construção porosos, frequentemente, tem uma relação direta com a raiz quadrada do tempo de exposição de acordo com a Equação (1) [26]:

$$
i=S t^{1 / 2}+C t
$$

onde $t$ é o tempo, $S$ é absortividade do material e $C$ é um parâmetro experimental. Nessa situação, a relação entre $i$ e $t^{1 / 2}$ é não linear e a absortividade e o parâmetro $C$ serão obtidos pelo ajuste da equação (1) com a curva experimental obtida para cada uma das misturas avaliadas.

O ensaio de absorção capilar permite ainda a determinação do coeficiente de absorção de água por capilaridade $\mathrm{K}=(\mathrm{Ma}-\mathrm{M}) / \mathrm{A}$, onde Ma é a massa do corpo de prova, após a absorção de água tornar-se constante, $\mathrm{M}$ é a massa do corpo de prova antes do ensaio e A é a área de seção transversal do corpo de prova em contato com a água. $\mathrm{O}$ valor de $\mathrm{K}$ corresponde ao máximo valor de $\mathrm{i}$, ou seja, o ponto a partir do qual a rela- 
ção i x t $\mathrm{t}^{1 / 2}$ passa a ser praticamente constante.
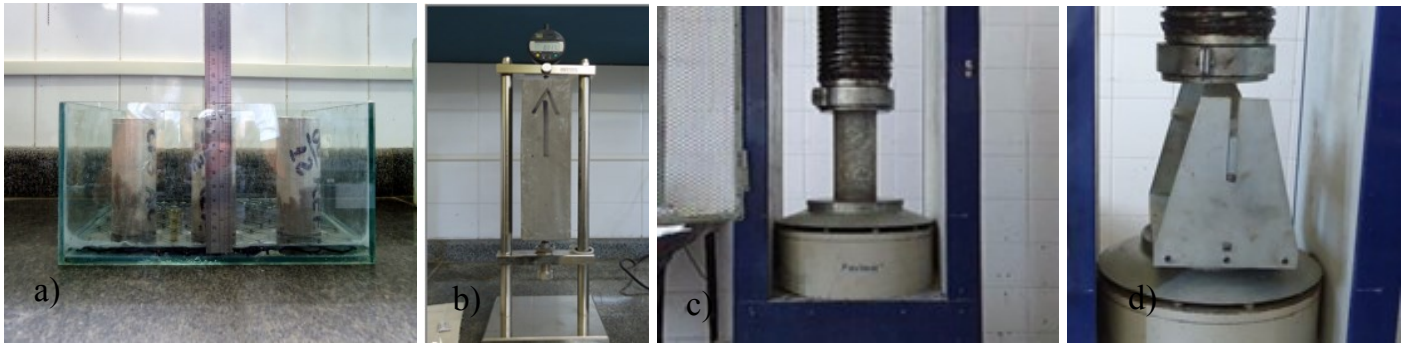

Figura 2: Configuração dos ensaios: a) Absorção de água por capilaridade; b) Retração por secagem; c) Resistência à compressão axial; d) Resistência à tração por compressão diametral.

\section{RESULTADOS}

\subsection{Estado fresco}

De modo a verificar a autoadensibilidade das matrizes foi realizado o ensaio de mini slump. O teor de aditivo superplastificante foi dosado para que todas as matrizes obtivessem um espalhamento de $140 \pm 10 \mathrm{~mm}$. Para a matriz de referência (REF) e com $10 \%$ de agregado reciclado (10RC), um teor de $24,71 \mathrm{~kg} / \mathrm{m} 3$ de aditivo foi suficiente para manter a trabalhabilidade desejada, como mostra a Figura 3a.

Para a mistura com $20 \%$ de agregado reciclado (20RC), no entanto, foi observado que o espalhamento reduziu para cerca de $100 \mathrm{~mm}$, como mostra a figura 3b. A maior quantidade de finos, maior absorção e uma superfície mais rugosa do grão estão entre as principais características do agregado reciclado, em comparação com o agregado natural, que afetam a reologia da argamassa no estado fresco [14] e reduzem a sua consistência. Saiz-Martínez et al. [27] indica que o aumento do teor de superplastificante ou o ajuste do teor de água da mistura podem contribuir para a obtenção de uma trabalhabilidade adequada. $\mathrm{O}$ aumento do teor de aditivo, para $30,86 \mathrm{~kg} / \mathrm{m} 3$, foi usado na matriz com $20 \%$ de agregado reciclado, como mostra a Tabela 2 , para que todas as matrizes atingissem o espalhamento desejado.
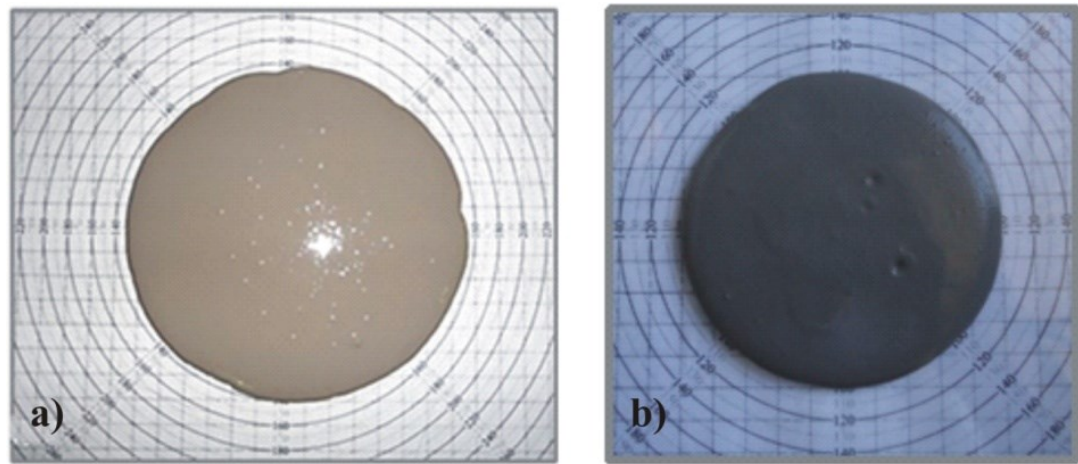

Figura 3: Espalhamento da mistura: a) com $20 \%$ de RC; b) matriz de referência

\subsection{Propriedades físicas}

A Tabela 3 apresenta os valores médios, com coeficiente de variação, das propriedades obtidas nos ensaios de absorção de água por imersão e por capilaridade. Um comparativo de médias utilizando o teste de Tukey é também apresentado na Tabela 3 onde, para cada propriedade, valores com letras iguais representam médias estatisticamente iguais. 
Tabela 3: Resultados dos ensaios físicos (coeficiente de variação, em \%, entre parênteses)

\begin{tabular}{|c|c|c|c|c|c|c|}
\hline \multirow[b]{2}{*}{ Misturas } & \multicolumn{2}{|c|}{ Absorção por imersão } & \multicolumn{3}{|c|}{ Absorção por capilaridade } & \multirow[b]{2}{*}{$\begin{array}{c}\text { Índice de } \\
\text { desempenho } \\
\text { ID }\left(\mathrm{g} / \mathrm{cm}^{2} \cdot \mathbf{h}^{1 / 2}\right)^{-1}\end{array}$} \\
\hline & Absorção (\%) & $\begin{array}{c}\text { Porosidade } \phi \\
\text { (\%) }\end{array}$ & $\begin{array}{c}\text { Absorção por } \\
\text { capilaridade } \\
\text { K }\left(\mathrm{g} / \mathrm{cm}^{2}\right)\end{array}$ & $\begin{array}{c}\text { Absortividade } \\
\mathbf{S}\left(\mathrm{g} / \mathrm{cm}^{2} \cdot \mathbf{h}^{1 / 2}\right)\end{array}$ & $\begin{array}{c}\text { Parâmetro c, } \\
\text { eq.(1) } \\
\left(\mathbf{g} / \mathbf{c m}^{2} \cdot \mathbf{h}^{-1}\right)\end{array}$ & \\
\hline REF & $19.28^{\mathrm{a}}(0.9)$ & $29,52^{\mathrm{a}}(0,9)$ & $2,83^{\mathrm{a}}(0.9)$ & $0,60^{\mathrm{a}}(0,9)$ & $\begin{array}{c}-0,0327^{\mathrm{a}} \\
(2,3)\end{array}$ & 1,175 \\
\hline $10 \mathrm{RC}$ & $21,08^{\mathrm{b}}(1,1)$ & $32,60^{\mathrm{b}}(1,0)$ & $3,19^{\mathrm{b}}(2.6)$ & $0,59^{\mathrm{a}}(1,2)$ & $\begin{array}{c}-0,0285^{\mathrm{b}} \\
(2,5)\end{array}$ & 1,142 \\
\hline $20 \mathrm{RC}$ & $21,53^{\mathrm{c}}(0,6)$ & $32,17^{\mathrm{b}}(0,1)$ & $3,14^{\mathrm{b}}(1.5)$ & $0,58^{\mathrm{a}}(4,3)$ & $\begin{array}{c}-0,0277^{\mathrm{b}} \\
(2,5) \\
\end{array}$ & 1,169 \\
\hline
\end{tabular}

* Dentro de cada grupo, letras iguais representam médias estatisticamente iguais

\section{a) Absorção de água por imersão e porosidade}

A Figura 4 demonstra que a introdução do agregado reciclado provoca um aumento da absorção e porosidade das matrizes recicladas, quando comparadas com a matriz produzida com agregado natural.

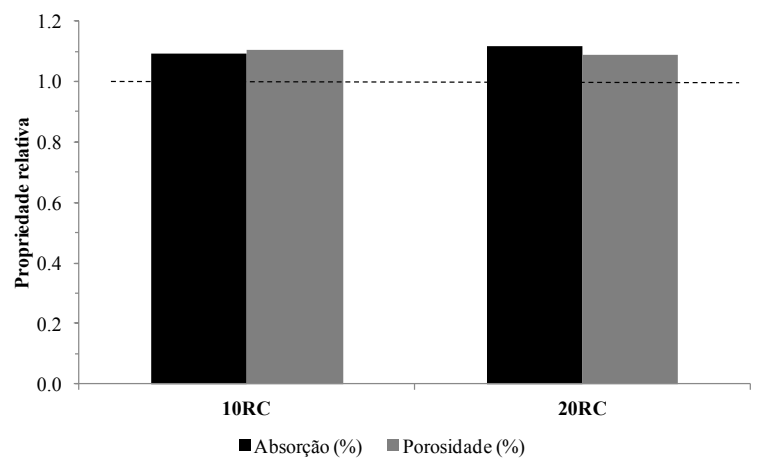

Figura 4: Influência do teor de agregado sobre as propriedades físicas das matrizes recicladas, relativa a matriz com agregado natural.

A absorção de água das misturas 10RC e 20RC foram, respectivamente, 9,33\% e 11,67\% maiores que a mistura REF. Esse comportamento é justificado por Lima e Leite [17] e Oliveira [28] pelo aumento da porosidade do agregado, com relação ao agregado natural. De fato, observando a Tabela 1, verifica que o agregado reciclado utilizado apresenta uma absorção de água muito maior que o agregado natural. É importante observar, no entanto, que o aumento na absorção não foi proporcional ao teor de agregado reciclado, visto que, a variação de $10 \%$ para $20 \%$ de RC resultou num incremento de apenas 2,34\% na absorção. Fato similar foi também observado para a porosidade, cujas matrizes recicladas apresentaram médias estatisticamente iguais, mas superiores à matriz de referência em até $10,4 \%$.

\section{b) Absorção de água por capilaridade}

Para as argamassas avaliadas neste estudo, verifica-se na Figura 5 uma não-linearidade da relação i- $t / 2$. Este fato foi também observado por Hall e Tse [26] na avaliação de argamassas e atribuído ao efeito da gravidade, o que é comum em materiais que apresentam macroporos e estrutura porosa mais aberta. A partir da correlação entre a equação (1) e as três curvas experimentais obtidas neste trabalho, para cada mistura, mostradas na Figura 5, foi possível obter os valores de absortividade $S$ e da constante experimental $C$ apresentados na Tabela 3 .

A absorção de água por capilaridade, índice $\mathrm{K}$ na Tabela 3, apresenta comportamento similar à absorção por imersão, com aumento de até $12,7 \%$ com a introdução do agregado reciclado. Zega e Di Maio [29] encontraram a mesma taxa (13\%) de aumento de absorção capilar ao utilizar agregado reciclado fino na produção de concretos. Esse aumento da absorção capilar foi atribuído pelos autores à maior absorção do agregado reciclado, em comparação ao natural, o que também foi verificado neste artigo, como pode ser verificado na Tabela 1. A comparação entre absorção de água por capilaridade e absorção de água por imersão, mostrada na Figura 6, demonstra que existe uma correlação linear entre elas para as misturas estudadas. 
Os valores de absortividade estão apresentados na Tabela 3. A absortividade está relacionada à difusividade hidráulica, pois representa a velocidade de penetração da água nos momentos iniciais e é dependente das características superficiais da argamassa. Diferentemente da absorção por imersão, que é influenciada pela pressão hidráulica, a absortividade é função da absorção capilar, estabelecida pela diferença de pressão entre a superfície livre do líquido, que entra em contato com o sólido poroso, e a superfície do mesmo líquido dentro do capilar.

A redução da absortividade é observada com a adição do agregado reciclado, mesmo com aumento da porosidade. As mudanças na porosidade ocorrem pela eliminação ou redução de poros maiores, e são estes poros que primariamente afetam a curvatura no gráfico de absortividade [30]. Essa correlação inversa entre porosidade e absortividade já foi observada por outros autores [31,32] em argamassas contendo adições minerais, uma vez que a presença de materiais finos influenciam na distribuição do tamanho de poros e continuidade da estrutura de poros capilares, podendo gerar uma rede porosa com diâmetros menores e, provavelmente, mais refinada, o que dificulta a penetração de água. Por essa razão, a absortividade é influenciada pela elevada percentagem de finos, inertes, presentes no material [33]. Dessa forma, o efeito negativo da absorção do agregado reciclado é compensada pelo efeito filer dos grãos menores que 75 microns presentes no agregado reciclado (ver Tabela 1) que geram um empacotamento da mistura e que resulta no possível refinamento dos poros.

Além do efeito de empacotamento dos grãos finos do agregado reciclado, outros fatores que afetam a absortividade estão associados à utilização da matriz autoadensável. O maior teor de superplastificante nas misturas com agregado reciclado podem ter influenciado no valore de absortividade, visto que, em argamassas, o aumento no teor deste aditivo reduz o valor absortividade S e do parâmetro C [29]. De acordo com Evangelista e Brito [12], a utilização de materiais cimentícios suplementares em substituição ao cimento, como a metacaolinita e cinza volante utilizados neste trabalho, podem reverter o efeito negativo sobre a absortividade de concretos produzidos com agregado reciclado.
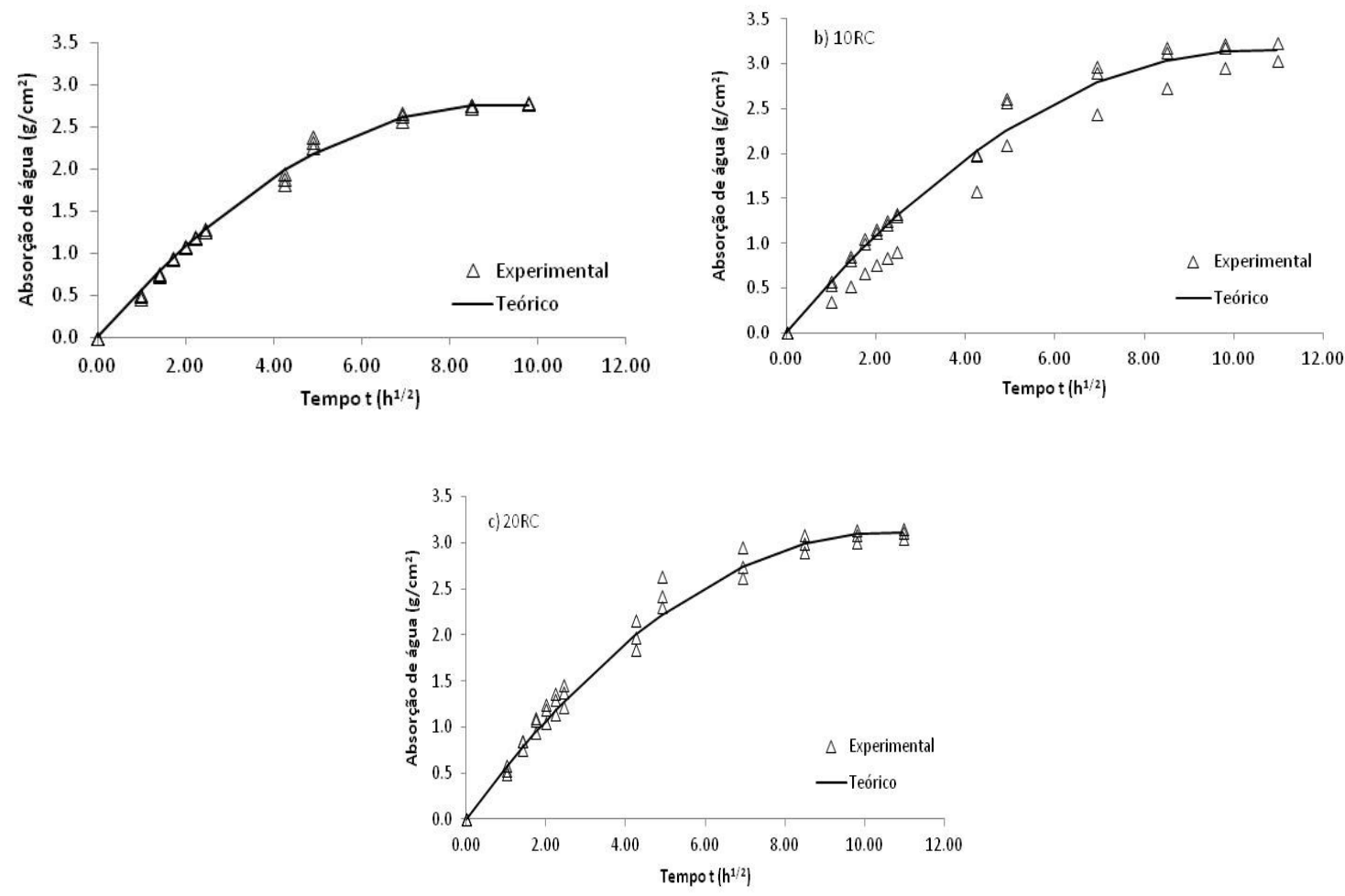

Figura 5: Curvas de absorção de água por capilaridade ao longo do tempo: a) matriz natural; b, c) matrizes recicladas. 


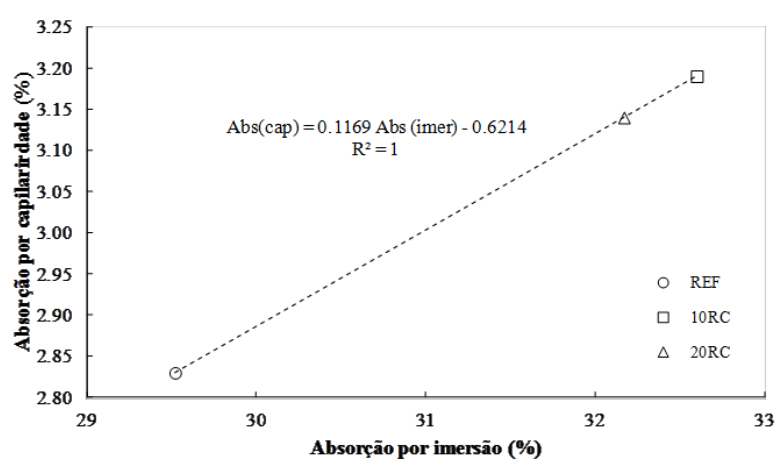

Figura 6: Correlação entre absorção por imersão e absorção por capilaridade para as matrizes.

Como as argamassas possuem absortividades praticamente iguais mas porosidades diferentes, é de se esperar que possuam diferentes resistências à penetração de água. A relação entre a porosidade acessível à água e a habilidade de penetração do líquido num meio poroso é definida como índice de desempenho (ID) do material [31], dado:

$$
I D=\frac{1-\emptyset}{\mathrm{S}}
$$

onde $\phi$ é a porosidade e $S$ é absortividade do material.

O ID indica o grau de dificuldade de um líquido penetrar e permanecer escoando no meio poroso. Para as matrizes estudadas neste trabalho, verifica-se, na Tabela 3, que a argamassa de referência possui maior ID, ou seja, maior resistência à penetração de água. No entanto, a introdução do agregado reciclado reduziu essa resistência em apenas $2.8 \%$, o que indica, então, que a matriz autoadensável com agregado reciclado tende a apresentar o comportamento similar, frente à ação dos agentes agressivos, que a matriz com agregado natural.

\section{c) Retração por secagem}

Na Figura 7-a, estão apresentadas as curvas médias, obtidas de três resultados experimentais, por mistura, de retração por secagem das misturas de referência (REF) e das misturas com substituição da areia natural por resíduo de concreto (10RC e 20RC), e na Figura 7-b suas respectivas perdas de massa.

Verifica-se que a taxa de retração da mistura REF (linha cheia na Figura 7-a) é mais intensa nos sete primeiros dias e torna-se praticamente constante, e próxima de zero, a partir dos sessenta dias de ensaio. Um aumento da retração com a adição do agregado reciclado pode ser observado comparativamente à argamassa de referência. Para a mistura 20RC, na idade de 70 dias, houve um acréscimo deste parâmetro de $1036 \mu \varepsilon$ para $1140 \mu \varepsilon$, ou seja, um aumento de cerca de $10 \%$. Essa taxa de incremento pode ser considerada aceitável, visto que para argamassas recicladas, tem sido relatado, que os valores de retração são o dobro do observado para argamassa com agregado natural $[17,27]$. Para argamassas com $25 \%, 50 \%$ e $75 \%$ de agregado reciclado misto (contendo grãos de concreto, cerâmica e argamassa), foram observados aumentos de $44 \%, 89 \%$ e $146 \%$, na retração aos 28 dias, em relação a argamassa produzida com agregado miúdo natural [28].

$\mathrm{O}$ aumento da retração na argamassa reciclada está diretamente associado à maior quantidade de água armazenada nos poros dos agregados reciclados e à estrutura mais porosa da matriz reciclada que facilita a saída desta água, ao longo do tempo, e provoca maior retração. No caso das matrizes autoadensáveis desenvolvidas neste trabalho, onde a absortividade foi pouco afetada pela presença do agregado reciclado, a movimentação de água dentro da estrutura da matriz reciclada, que depende das características dos poros e capilares, é similar à da matriz com agregado natural, o que certamente contribuiu para uma menor intensidade de retração, quando comparada com as demais argamassas recicladas relatadas na literatura.

Quando a argamassa está exposta à umidade do ambiente há uma tendência a entrar em equilíbrio, sendo que em atmosferas secas a superfície exposta da argamassa perde água por evaporação. A primeira parcela de perda de água corresponde àquela água retida nos maiores poros capilares do concreto endurecido e que não causam variação de volume significativa. No entanto, com a continuidade da secagem, acontece a perda de água dos pequenos poros capilares e posteriormente do gel dos poros. Com a redução da pressão de vapor no poro capilar, tensões de tração na água residual nos capilares aumenta e são balanceadas por tensões de compressão que causam a retração do concreto. A evaporação da água do gel muda a energia superficial 
da fase sólida e causa maior retração. Como resultado da interação entre esses mecanismos, a relação entre a deformação de retração e a perda de umidade apresenta um comportamento não linear com pontos de descontinuidade, como mostra a Figura $7 \mathrm{~b}$.

Os trechos de reta OAB, definidos por Mesbah e Bodyl [34], associam a perda de água ao tipo de vazio presente no material; o trecho $\mathrm{OA}$ corresponde à saída de água contida nos maiores poros capilares e apresenta menor inclinação que o trecho $\mathrm{AB}$, que indica a perda de água contida em vazios capilares. Ou seja, para a mesma percentagem de perda de água, a saída de água dos vazios capilares resulta em maior deformação por retração da argamassa. Avaliando a influência do agregado reciclado, verifica-se que a inclinação do primeiro trecho OA é menos acentuada para a argamassa natural, indicando que nessa matriz a perda maior de água acontece de poros maiores do que aqueles presentes na argamassa reciclada e, por isso, uma menor retração é esperada. Para uma deformação de $620 \mu \varepsilon$, a perda de água para a argamassa natural e argamassas com $10 \%$ e $20 \%$ de agregado reciclado são de $7,8 \%, 6,8 \%$ e $7,5 \%$, respectivamente. No trecho $\mathrm{AB}$, as inclinações de todas as curvas são similares, indicando que a retração de todas as matrizes neste trecho é causada pela perda de água de vazios capilares.
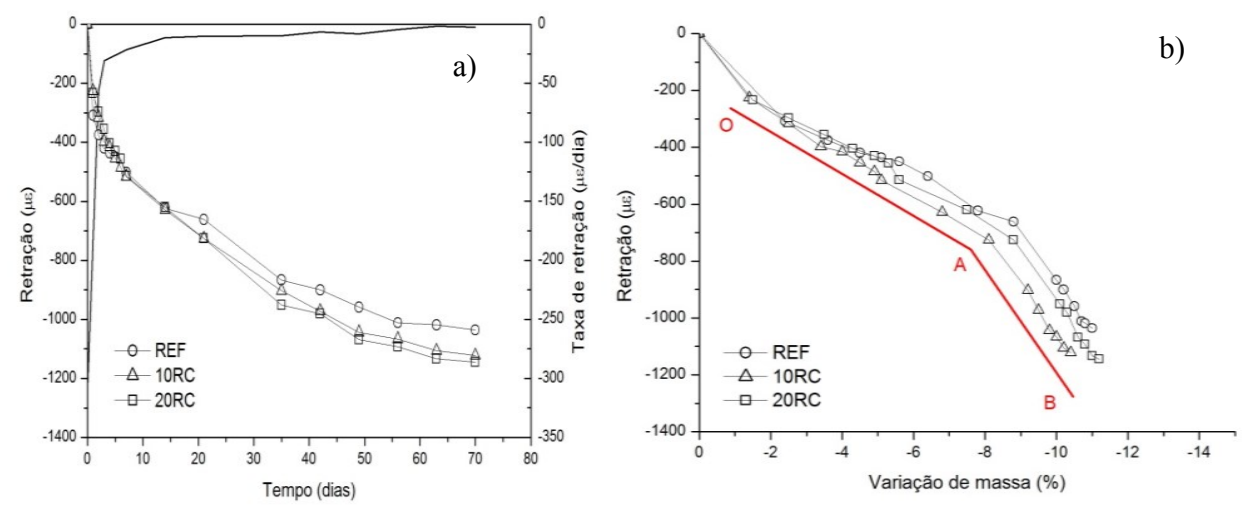

Figura 7: Efeito do agregado reciclado sobre a) retração por secagem e b) perda de massa das argamassas.

\subsection{Resistência mecânica}

Os resultados dos ensaios mecânicos de resistência à compressão axial (fc) e resistência à tração por compressão diametral (ftd), de matrizes e compósitos, são apresentados na Tabela 4.

Tabela 4: Resultados dos ensaios mecânicos (coeficiente de variação, em \%, entre parênteses)

\begin{tabular}{ccc}
\hline MISTURA & $\begin{array}{c}\text { fc } \\
\text { (MPa) }\end{array}$ & $\begin{array}{c}\text { ftd } \\
\text { (MPa) }\end{array}$ \\
\hline \multicolumn{3}{c}{ Grupo 1: matrizes } \\
\hline REF & $30,42^{\mathrm{a}}(0,8)$ & $2,13^{\mathrm{a}}(11,6)$ \\
10RC & $30,24^{\mathrm{a}}(0,3)$ & $2,09^{\mathrm{a}}(19,4)$ \\
20RC & $31,27^{\mathrm{b}}(2,0)$ & $2,06^{\mathrm{a}}(15,5)$ \\
\hline \multicolumn{3}{c}{ Grupo 2: Compósitos com $4 \%$ de fibras } \\
\hline REF4 & $18,66^{\mathrm{c}}(1,1)$ & $2,23^{\mathrm{b}}(1,1)$ \\
10RC4 & $18,91^{\mathrm{c}, \mathrm{d}}(4,19)$ & $2,22^{\mathrm{b}}(3,0)$ \\
20RC4 & $17,86^{\mathrm{d}}(3,5)$ & $2,21^{\mathrm{b}}(1,8)$ \\
\hline \multicolumn{3}{c}{ Grupo $3:$ Compósito com $6 \%$ de fibras } \\
\hline REF6 & $18.07^{\mathrm{e}}(2,9)$ & $1,95^{\mathrm{c}}(0,7)$ \\
10RC6 & $17,17^{\mathrm{f}}(3,1)$ & $1,93^{\mathrm{c}}(9,7)$ \\
20RC6 & $15,78^{\mathrm{g}}(1,9)$ & $1,88^{\mathrm{c}}(3,3)$ \\
\hline
\end{tabular}

* Dentro de cada grupo, letras iguais representam médias estatis- 


\section{a) Influência do agregado reciclado}

Comparando-se os pares de médias através do teste de Tukey verifica-se que, para as matrizes (Grupo 1), a mistura com $20 \%$ de agregado reciclado (RC) apresentou diferença significativa das demais, com um aumento de $2,8 \%$, com relação a argamassa com agregado natural, devido ao melhor empacotamento das partículas.

Para os compósitos com 4\% de fibra (Grupo 2), houve, por outro lado, uma redução da resistência de $5,6 \%$ com a utilização de $20 \%$ de RC. Para os compósitos com $6 \%$ de fibras (grupo 3), verifica-se uma redução significativa de resistência com a adição de $10 \%$ e $20 \%$ de RC, da ordem de $5 \%$ e $12,7 \%$, respectivamente.

Verifica-se um efeito diferenciado do agregado reciclado entre matriz e compósitos, que pode ser atribuído à interação entre o agregado e as fibras, visto que ambos apresentam alta absorção de água e podem afetar o processo de mistura e lançamento da argamassa.

Os valores de resistência à tração por compressão diametral, dentro dos grupos, não foram afetados pela presença do agregado reciclado e apresentaram médias estatisticamente iguais, de acordo com o teste de Tukey.

\section{b) Influência da fibra}

A utilização de fibras curtas randomicamente distribuídas nas matrizes a base de cimento frequentemente reduz a sua resistência a compressão; as fibras reduzem a trabalhabilidade do material em estado fresco e durante os processos de mistura e lançamento uma maior quantidade de ar é incorporada. Como resultado, a matriz do compósito apresenta maior porosidade que a matriz misturada separadamente [35], e consequentemente menor resistência mecânica. Dentre os fatores que interferem nesse fenômeno estão as características da fibra (tipo, volume e comprimento), características de matriz (tipo e granulometria do agregado, fator água-cimento, uso de adições e aditivos, etc.) e mesmo o tipo de misturador utilizado. Utilizando matrizes de argamassa convencionais (sem aditivos químicos ou adições minerais), no traço 1:1:0,4 (cimento:areia:fator água/cimento), em massa, Lima [36] observou uma redução de resistência à compressão de 7,89\%, 23,28\% e $24,90 \%$, com a introdução de $1 \%, 2 \%$ e $3 \%$ de fibras de sisal com $25 \mathrm{~mm}$ de comprimento, respectivamente.

Na Figura 8 observa-se tendência de redução da resistência à compressão do compósito com o aumento do teor de fibra, para todas as misturas, com e sem agregado reciclado. Para adição de $4 \%$ e $6 \%$ de fibras, com $40 \mathrm{~mm}$ de comprimento, a redução foi de 38,7\% e 40,6\%, respectivamente. Utilizando $10 \%$ de agregado reciclado, verifica-se um decréscimo de $37,5 \%$ e 43,2\% na resistência à compressão, com a adição de $4 \%$ e $6 \%$ de fibras, respectivamente, enquanto que, para o uso de $20 \%$ de agregado reciclado essas reduções são de $42,8 \%$ e 49,0\%, para os respectivos teores de fibra. Em comparação, com o uso de uma matriz convencional com traço, em massa, de 1:1:0,45 (cimento:areia:fator/água cimento), mas com adição de superplastificante, Lima et al. [20] encontraram valores de redução de $30 \%$ e $50 \%$ na resistência à compressão com a introdução $4 \%$ e $6 \%$ de fibras de sisal de $25 \mathrm{~mm}$. Verifica-se, portanto, que as características de autoadensabilidade da matriz utilizada, como uso de adições minerais, controle do tamanho do grão e aditivos, permitiu a produção de um compósito com maior comprimento de fibra e que conseguiu minimizar o efeito negativo sobre a resistência à compressão causado pela introdução de maiores teores de fibras, mesmo com a utilização de agregado reciclado.

Considerando que a menor resistência à compressão obtida foi de cerca de $15 \mathrm{MPa}$, verifica-se que os compósitos reciclados produzidos tem potencialidade, em termos de resistência mecânica, para ser utilizado na produção de elementos construtivos.

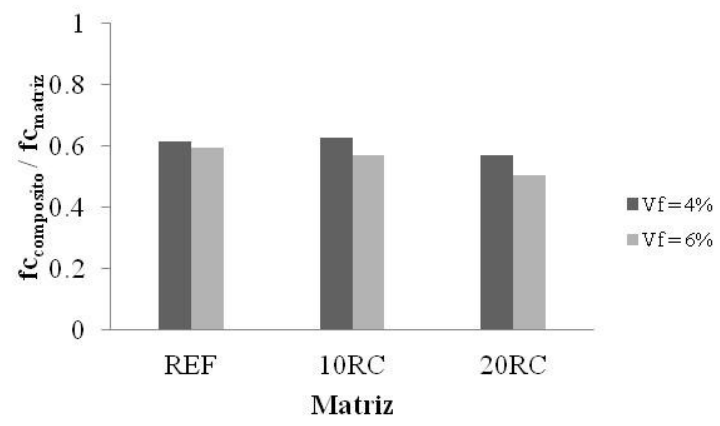

Figura 8: Influência das fibras na resistência à compressão de matrizes convencional e recicladas. 


\section{c) Interação entre agregado reciclado e fibras}

Para determinação do efeito da interação entre volume de fibra e agregado reciclado sobre a resistência à compressão foi realizado um planejamento estatístico do experimento $3^{2} \operatorname{com} 2$ fatores e 3 níveis, baixo, alto e intermediário: fator RC (volume de agregado reciclado), com níveis 0, 10 e 20\%; e fator 2: VF (fração volumétrica das fibras), com níveis $0,4 \%$ e $6 \%$.

A partir dos resultados apresentados na Tabela 4, foi possível obter um modelo de regressão múltipla que relaciona a resistência à compressão com os fatores estudados:

$$
\mathrm{f}_{\mathrm{c}}=30,13+0,067 \cdot \mathrm{RC}-4,324 \cdot \mathrm{VF}-0,001 \cdot \mathrm{RC}^{2}+0.384 \cdot \mathrm{VF}^{2}-0,025 \cdot \mathrm{RC} \cdot \mathrm{VF}
$$

A representação gráfica da equação (3), mostrada na Figura 9, demonstra que a relação fc-VF é fortemente não linear, reduzindo com o aumento do volume de fibra. A relação fc-RC é linear, sendo que, devido à interação com o volume de fibra, verifica-se na Figura 8 que, enquanto na matriz $(\mathrm{VF}=0)$, a resistência aumenta com o teor de $\mathrm{RC}$, para compósitos com $\mathrm{VF}=6 \%$, há uma redução de resistência com o aumento de $\mathrm{RC}$.

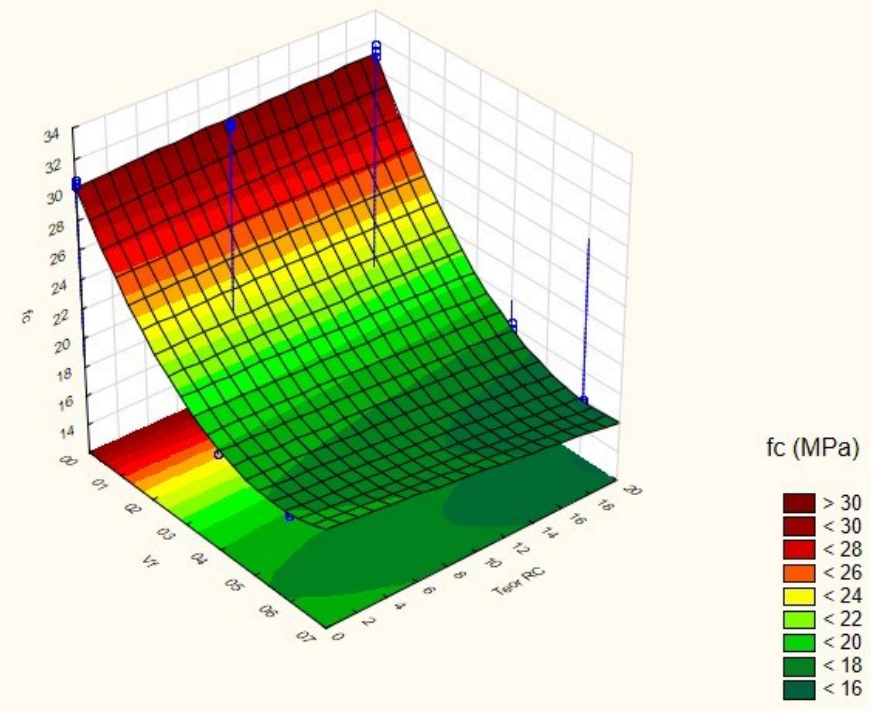

Figura 9: Efeito da interação entre volume de fibras (VF) e teor de agregado reciclado (RC) sobre a resistência compressão (fc).

A interação entre VF e RC pode também ser avaliada pela forma das curvas de nível; para pequeno volume de fibra, as curvas são aproximadamente paralelas, ou seja, para o mesmo volume de fibra a resistência mecânica independe de RC; para volume de fibra maior que 4\% as curvas apresentam formato parabólico, indicando que a influência de VF sobre a resistência depende do teor de agregado reciclado RC.

A avaliação da resistência à tração por compressão diametral pelo projeto de experimentos resulta na equação (4), apresentada graficamente na Figura 10.

$$
\mathrm{f}_{\mathrm{td}}=2,12-0,002 \cdot \mathrm{RC}+0,151 \cdot \mathrm{VF}-0.030 \cdot \mathrm{VF}^{2}
$$

Verifica-se que as curvas de nível são paralelas, ou seja, não há interação entre VF e RC. De fato, observando a Figura 10 é identificado que o valor de resistência à tração, para um determinado volume de fibras, não é afetado quando se aumenta o teor de RC, comprovando o resultado do teste de Tukey mostrado na Tabela 4. O efeito isolado da fibra, no entanto, é efetivo, com aumento da resistência para fração volumétrica de $4 \%$ e redução de resistência para $6 \%$, com relação à resistência da matriz. Era esperado um aumento da resistência à tração com a presença das fibras devido ao efeito de costura das microfissuras [35], no entanto, para maiores teores o efeito negativo sobre porosidade e resistência mecânica sobrepõe essa contribuição na região fissurada. 




Figura 10: Efeito da interação entre volume de fibras (VF) e teor de agregado reciclado (RC) sobre a resistência à tração por compressão diametral (ftd).

\section{CONCLUSÕES}

Com os resultados apresentados pode-se concluir que, a substituição de agregado natural por $10 \%$ e $20 \%$ de agregado reciclado de concreto manteve a resistência à compressão e a absortividade das misturas, apesar do aumento na porosidade. Esse fato está associado à dosagem de uma matriz autoadensável, que permitiu melhor distribuição e empacotamento das partículas resultando na formação de uma estrutura de poros mais refinada. De fato, o aumento esperado da absorção de água e na retração por secagem das argamassas recicladas foi inferior ao observado por outros pesquisadores, que usaram o mesmo teor de agregados reciclados, mas em matrizes convencionais (sem aditivos e adições).

Devido à maior fluidez das matrizes, foi possível incorporar $4 \%$ e $6 \%$ de fibras de sisal com $40 \mathrm{~mm}$ de comprimento e manter a trabalhabilidade dos compósitos. O resultado mecânico demonstrou que os compósitos produzidos com agregado natural ou reciclado apresentaram valores de resistência mecânica compatíveis com aqueles relatados na literatura, mas com maior índice de reforço de fibra, o que amplia a aplicabilidade do material.

O efeito da interação entre fibra e agregado reciclado foi estatisticamente mais importante para maiores teores, o que indica que o uso simultâneo desses materiais deve ser compatível com a aplicação em elementos construtivos.

Diante do exposto conclui-se que o uso de agregado reciclado de concreto é viável na produção de matriz autoadensável, visto que a matriz reciclada mostrou-se adequada para a produção de compósitos com elevado teor de fibra $(4 \%$ e $6 \%)$.

\section{AGRADECIMENTOS}

Os autores agradecem à Coordenação de Aperfeiçoamento de Pessoal de Nível Superior (Projeto CAPES PVE 047/2012), FAPESB (Bolsa de Mestrado) e ao CNPq pelo apoio.

\section{BIBLIOGRAFIA}

[1] DEPARTAMENTO NACIONAL DE PRODUÇÃO MINERAL. Areia Construção - Sumário Mineral 2014. Brasília, 2015.

[2] ASSOCIAÇÃO BRASILEIRA DE EMPRESAS DE LIMPEZA PÚBLICA E RESÍDUOS ESPECIAIS (ABRELPE). Panorama dos resíduos sólidos no Brasil 2012., São Paulo, Disponível em http://www.abrelpe.org.br/dowloads/panorama2012.pdf. Acesso em abril. 2014

[3] SATYANARAYANA, K.G, GUIMARÃES, J.L., WYPYCH, F. "Studies on lignocellulosic fibres of Brazil. Part I: Source, production, morphology, properties and applications", Composites Part A: Applied Science and Manufacturing, v. 38, n. 7, pp. 1694-1709, 2007. 
[4] FERREIRA, S. R. Influência da hornificação na aderência fibra-matriz e no comportamento mecânico de compósitos cimentíceos reforçados com fibras de sisal, Dissertação de M.Sc., PPGECEA/UEFS, Feira de Santana, BA, Brasil, 2012.

[5] TONOLI, G.H.D., SANTOS, S.F., SANTOS, J.A., et al., "Thermal performance of sisal fiber-cement roofing tiles for rural constructions", Scientia Agricola, v.68, n.1, p.1-7, Piracicaba, 2011.

[6] MONTEIRO, S.N., AQUINO, R.C.M.P., LOPES, F.P.D., et al., "Tenacidade ao entalhe por impacto Charpy de compósitos de poliéster reforçados com fibras de piaçava", Matéria, v. 11, n. 3, july/sept., 2006.

[7] BLUNT, J, OSTERTAG, C. "Deflection hardening and workability of hybrid fiber composites", $A C I M a$ terials Journal, v. 106, pp. 265-272, 2009.

[8] JIN-KEUN, K., JEONG-SU, K., HA, G.J., et al., "Tensile and fibre dispersion performance of ECC (engineered cementitious composites) produced with ground granulated blast furnace slag", Cement and Concrete Research, v. 37, n. 7, pp. 1096-1105, 2007.

[9] LIMA, P.R.L., TOLEDO FILHO, R.D., MELO FILHO, J.A. “Compressive stress-strain behaviour of cement mortar-composites reinforced with short sisal fibre”, Materials Research, v. 17, n. 1, pp. 38-46, 2013.

[10] ASSOCIAÇÃO BRASILEIRA DE NORMAS TÉCNICAS. NBR 15116: agregados reciclados de resíduos sólidos da construção civil: utilização em pavimentação e preparo de concreto sem função estrutural: requisitos. Rio de Janeiro, 12p, 2004.

[11] GONÇALVES, P., BRITO, J. "Utilização de agregados reciclados em betão. Análise comentada da regulamentação existente”, Engenharia Civil, UM (Universidade do Minho), n. 32, pp.73-86, 2008.

[12] EVANGELISTA, L., BRITO, J. "Durability Performance of Concrete Made With Fine Recycled Concrete Aggregates", Cement and Concrete Composites, v. 32, n. 1, pp. 9-14, 2010.

[13] CORINALDESI, V., MORICONI, G. "Influence of mineral additions on the performance of $100 \%$ recycled aggregate concrete", Construction and Building Materials, v. 23, pp. 2869-2876, 2009.

[14] LIMA, P.R.L., TOLEDO FILHO, R.D., GOMES, O.F.M. "Influence of Recycled Aggregate on the Rheological Behavior of Cement Mortar”, Key Engineering Materials (Online), v. 600, pp. 297-307, 2014.

[15] LEITE, M. B., FIGUEIREDO FILHO, J. G., LIMA, P.R.L. "Workability study of concretes made with recycled mortar aggregate", Materials and structures, v. 46, n. 10, pp. 1765-1778, 2013.

[16] LEITE, M. B. Avaliação de propriedades mecânicas de concretos produzidos com agregados reciclados de resíduos de construção e demolição., Tese de D.Sc., UFRGS, Rio Grande do Sul, RS, Brasil, 2001.

[17] LIMA, P.R.L., LEITE, M.B. "Influence of CDW Recycled Aggregate on Drying Shrinkage of Mortar", Open Journal of Civil Engineering, v. 2, pp. 53-57, 2012.

[18] DOMINGO-CABO, A., LÁZARO, C., LÓPEZ-GAYARRE, F., et al., "Creep and shrinkage of recycled aggregate concrete", Construction and Building Materials, v. 23, pp. 2545-2553, 2009.

[19] GRAM, H. E., PERSSON, H., SKARENDAHL, A. Natural fiber concrete., SAREC Report, 1984.

[20] LIMA, P.R.L., SANTOS, D.O.J., FONTES, C.M.A., BARROS, J.A.O., TOLEDO FILHO R.D. "Deflection hardening of sustainable fiber-cement composites", Green Materials, v. 4, n. 1, pp. 18-30, 2016.

[21] ASSOCIAÇÃO BRASILEIRA DE NORMAS TÉCNICAS. NBR 9778. Argamassa e concreto endurecidos - Determinação da absorção de água, índice de vazios e massa específica. Rio de Janeiro, 2005.

[22] ASSOCIAÇÃO BRASILEIRA DE NORMAS TÉCNICAS. NBR 9779. Argamassa e concreto endurecidos - Determinação da absorção de água por capilaridade. Rio de Janeiro, 1995.

[23] AMERICAN SOCIETY FOR TESTING AND MATERIALS. ASTM C 157: Length change of hardened hydraulic-cement mortar and concrete. U.S.A., 2003.

[24] ASSOCIAÇÃO BRASILEIRA DE NORMAS TÉCNICAS. NBR 5739. Concreto - Ensaio de compressão de corpos de prova cilíndricos. Rio de Janeiro, 2007.

[25] ASSOCIAÇÃO BRASILEIRA DE NORMAS TÉCNICAS. NBR 7222. Argamassa e concreto - Determinação da resistência à tração por compressão diametral em corpos de prova cilíndricos. Rio de Janeiro, 1994.

[26] HALL, C., TSE, T.K.M. "Water movement in porous building materials - VII. The sorptivity of mortars”, Building and Environment, v. 21, n. 2, pp. 113-118, 1996. 
[27] SAIZ-MARTÍNEZA, P., GONZÁLEZ-CORTINAA, M. , FERNÁNDEZ-MARTÍNEZB F. "Characterization and influence of fine recycled aggregates on masonry mortars properties", Materiales de Construcción, v. 65, n.319, July-September 2015.

[28] OLIVEIRA, M.E.D. Agregado reciclado de construção e demolição: influência em propriedades de argamassas para revestimento, Dissertação M.Sc., PPGECEA/UEFS, Feira de Santana, BA, Brasil, 2012.

[29] ZEGA, C.J., DI MAIO, A.A. "Use of recycled fine aggregate in concretes with durable requirements", Waste Management, v.31, n, 11, pp. 2336-2340, Nov. 2011.

[30] HALL, C. YAUT, M. H. R. "Water movement in porous building materials--ix. the water absorption and sorptivity of concretes", Building and Environment, v. 22, n. 1, pp. 77-82, 1987

[31] GONÇALVES, J., LIMA, P.R.L., TOLEDO FILHO, R.D., et al., "Penetração de água em argamassas de argila calcinada-cimento portland", In: Anais do V SBTA Simposio Brasileiro de Tecnologia das Argamassas, p.417-428, São Paulo, 11 a 13 de junho de 2003.

[32] MASSAZZA, F., COSTA, U., MARCHESE, B. "Capillary absorption and composition of pastes and mortars made with Portland and Pozzolanic cementes", In.. Proceeding of Durability of Building Materials and Components 6, p. 193 - 202, Edited by S. Nagataki, T., Nireki, Tomosawa, F., Spon, E.F.N. 1993

[33] COUTINHO, A. S. Fabrico e Propriedades do Betão, 3 ed, Laboratório Nacional de Engenharia Civil, Lisboa, 1997.

[34] MESBAH, H.A., BUYLE-BODIN, F. "Efficiency of polypropylene and metallic fibres on control of shrinkage and cracking of recycled aggregate mortars", Construction and Building Materials, v. 13, n. 8, pp. 439-447, 1999.

[35] NGOLLĖ, A., PÉRA, J., "Microstructural based modelling of the elastic modulus of fiber reinforced cement composites", Advanced cement based materials, v.6, pp.130-137, 1997.

[36] LIMA, P.R.L. Análise teórica e experimental de compósitos reforçados com fibras de sisal. Tese de D.Sc., COPPE/UFRJ, Rio de Janeiro, RJ, Brasil, 2004. 